\title{
Engineering of zinc finger and MHC motifs to locked-in tertiary folds
}

\author{
Marc Mathieu, Christian Lehmann, Alain Razaname and Gabriele Tuchscherer* \\ Institute of Organic Chemistry, University of Lausanne, BCH-Dorigny, CH-1015 Lausanne, Switzerland
}

Received 27 December 1996

Accepted 22 January 1997

Keywords: Protein design; Locked-in folds; Chemoselective ligation; Zinc finger motif; MHC motif;

Protein mimetics; Non-native architectures

\section{SUMMARY}

The assembly of helical and $\beta$-sheet peptide blocks containing reactive chain ends results in highly branched chain architectures ('locked-in folds') mimicking native tertiary structures. This molecular kit strategy allows to bypass the protein folding problem in protein de novo design and gives access to protein mimetics of high thermodynamic stability. The validity of this concept is exemplified for the design and synthesis of locked-in folds mimicking the zinc finger and MHC folding motifs.

\section{INTRODUCTION}

The construction of novel proteins from scratch is hampered by the low probability of linear polypeptides to fold into a unique, stable tertiary structure [1]. Since the complex folding mechanism has yet to be unraveled [2], we proposed some years ago a conceptually different approach in protein de novo design to bypass this well-known folding problem: the template assembled synthetic proteins (TASP) concept $[3,4]$. As a key element, a topological template [5,6] serves as a built-in device to induce and reinforce intramolecular interactions of the covalently attached amphipathic peptide blocks, thus leading to predetermined packing topologies such as $\alpha$-helical bundle or $\beta$-sheet TASP molecules. As a general feature,
TASP molecules adopt a globular structure showing cooperative denaturation behaviour similar to natural proteins [7,8]. Recent progress in the synthetic methodology for assembling peptides allows us now to access the full potential of the TASP concept. For example, in separating structural and functional domains of native proteins, we have recently established the use of templates (RAFT) as scaffolds for the assembly of receptor binding loops [9]. Here, we extend the TASP concept for the construction of multibranched, oligocyclic peptides, termed locked-in tertiary folds. These conformationally trapped folding units bypass the complex folding pathway of linear polypeptides and are thought to exhibit unique structural and physicochemical properties.

\footnotetext{
*To whom correspondence should be addressed.
} 
a

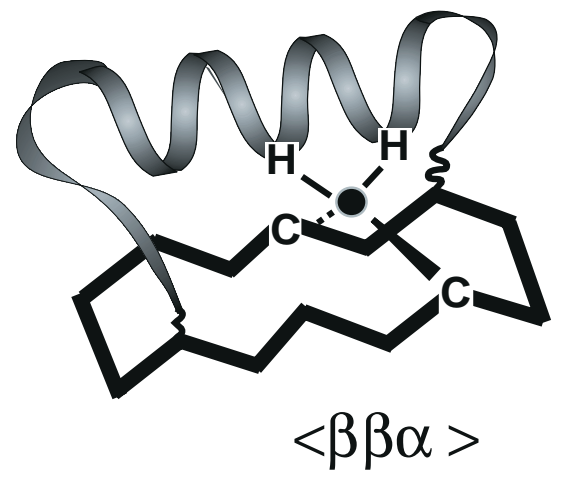

b

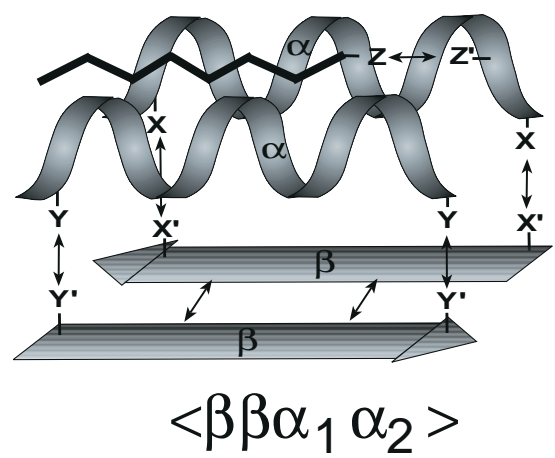

Fig. 1. Engineering of peptides: molecular kit ( $\alpha$-helices, $\beta$ sheets) for the construction of locked-in tertiary folds. (a) Zinc finger derived $\beta \beta \alpha$ folding unit with the appropriate geometry for $\mathrm{Zn}$ (II) complexation. (b) MHC derived $\beta \beta \alpha_{1} \alpha_{2}$ folding unit mimetic. X,X'; Y,Y', Z,Z': functional groups $\left(-\mathrm{CHO},-\mathrm{ONH}_{2}\right.$; -SH, - $\mathrm{CHBr}$ ) for covalently attaching the individual building blocks $\left(\alpha_{1}, \alpha_{2}\right.$, antigenic peptide) via chemoselective ligation techniques [12-14].

\section{RESULTS AND DISCUSSION}

Design of a zinc finger locked-in fold $\langle\beta \beta \alpha>$

According to the novel approach, the envisioned folding motif is set up by covalently linking the individual helical or $\beta$-sheeted peptide blocks at both chain ends via linkers onto templates to result in highly branched packing arrangements ('locked-in folds' (LIFs), Fig. 1). In contrast to regularly folded polypeptides, intramolecular long-range interactions are enforced here by trapping each secondary structure block at both chain ends, resulting in a conformationally restricted chain architecture with increased thermodynamic stability. In particular, the large number of alternative folding pathways and tertiary assemblies is considerably excluded within the depicted lockedin motifs.

The present concept is exemplified first for the design and chemical synthesis of a zinc finger (Zif) derived locked-in folding unit of type $\beta \beta \alpha$. So far, the Zif folding module has been the subject of numerous studies for delineating structurefunction relationships of this DNA-binding protein [10]. The consensus sequence

$$
\mathrm{Xaa}_{3}-\mathrm{Cys}-\mathrm{Xaa}_{2-4}-\mathrm{Cys}-\mathrm{Xaa}_{12} \mathrm{His}-\mathrm{Xaa}_{3-4}-\mathrm{His}_{-} \mathrm{Xaa}_{4}
$$

(Xaa denoting any amino acid) has been shown to fold in the presence of $\mathrm{Zn}$ (II) into a $\beta \beta \alpha$ folding unit [11] which binds via its helical part to a three base pairs subsite of the DNA. Multimeric zinc finger proteins, consisting of several Zif modules, are considered to play a key role in controlling gene expression [10]. In applying the concept of locked-in folds, the $\beta \beta \alpha$ framework of the Zif motif suggests the use of a topological template as a mimetic of the structural part and the covalent trapping of the bifunctional helical block as shown in Fig. 1a. To this end, the helix is covalently attached at both chain ends to the cyclic 14-mer template via amide bonds or by chemoselective ligation procedures [12-15] to result in a locked-in fold of type $\langle\beta \beta \alpha>$. It has been demonstrated earlier that cyclic peptide templates as depicted in Fig. 1 and Scheme 1 adopt preferentially an antiparallel $\beta$-sheet structure directing the $\varepsilon-\mathrm{NH}_{2}$ side chains of the lysine residues as attachment sites towards the same face of the template plane $[5,6]$.

Superposition of the X-ray structure of DNAbound Zif 268 and the conformationally relaxed zinc finger LIF reveals a nearly perfect match of the two molecules (Ref. 15, not shown here). Most notably, after the incorporation of cysteine and histidine residues in the template and helix, respectively (Scheme 1), the $\mathrm{Zn}$ (II) complexation site could be readily accommodated in the LIF molecule. 


\section{Template:}

$\mathrm{H}_{2} \mathrm{~N}$-Lys(Dde)-Pro-Gly-Cys(Tr)-Asp(O tBu)-Arg(Pmc)-Ala-Lys(Dde)-Pro-Gly-Phe-Ala-Cys(Trt)-Ala-Sasrin

1. cleavage from resin (5\% TFA)

2. cyclization (PyBOP, DMF)

3. - Dde $\left(10 \% \mathrm{H}_{2} \mathrm{NNH}_{2}\right.$ in DMF)

Helix:

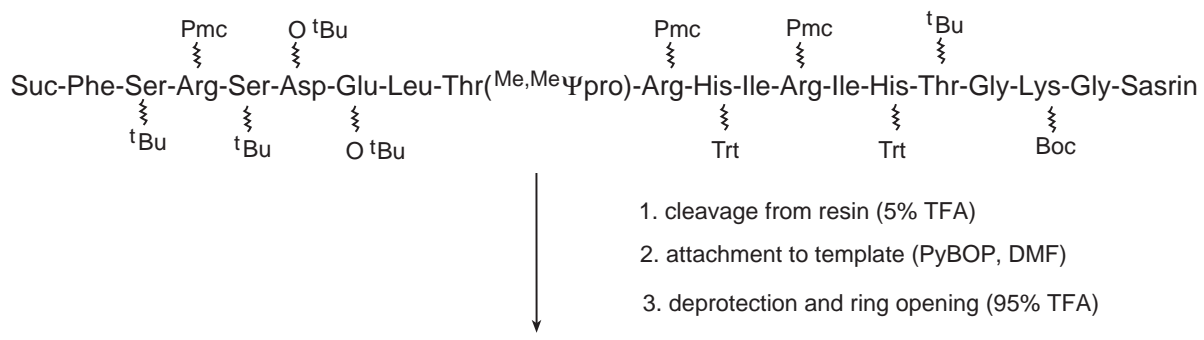

zinc finger LIF

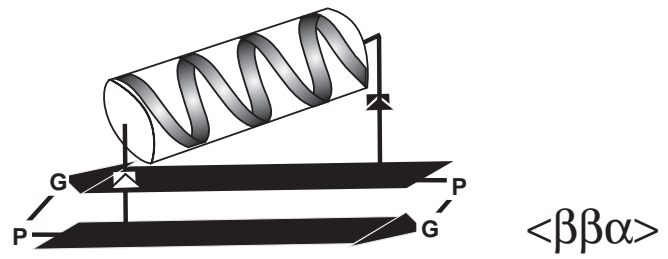

Scheme 1. Synthesis of the zinc finger molecule $\langle\beta \beta \alpha\rangle$. The orthogonally protected 14-mer template is prepared by Fmoc strategy based on solid phase peptide synthesis and cyclized in solution as described elsewhere [5]. In parallel, the helical block is cleaved from the Sasrin-resin to result in a fully protected peptide containing carboxy functions at both chain ends $\left(\mathrm{Suc}=\mathrm{HOOC}-\left(\mathrm{CH}_{2}\right)-\right.$ CO-). $\Psi$ Pro is used as a temporary protection of threonine to increase the solvation of the helical block during the condensation reaction to the template in solution. The target molecule $\langle\beta \beta \alpha>$ is obtained after simultaneous side-chain deprotection and $\Psi$ Pro ring opening.
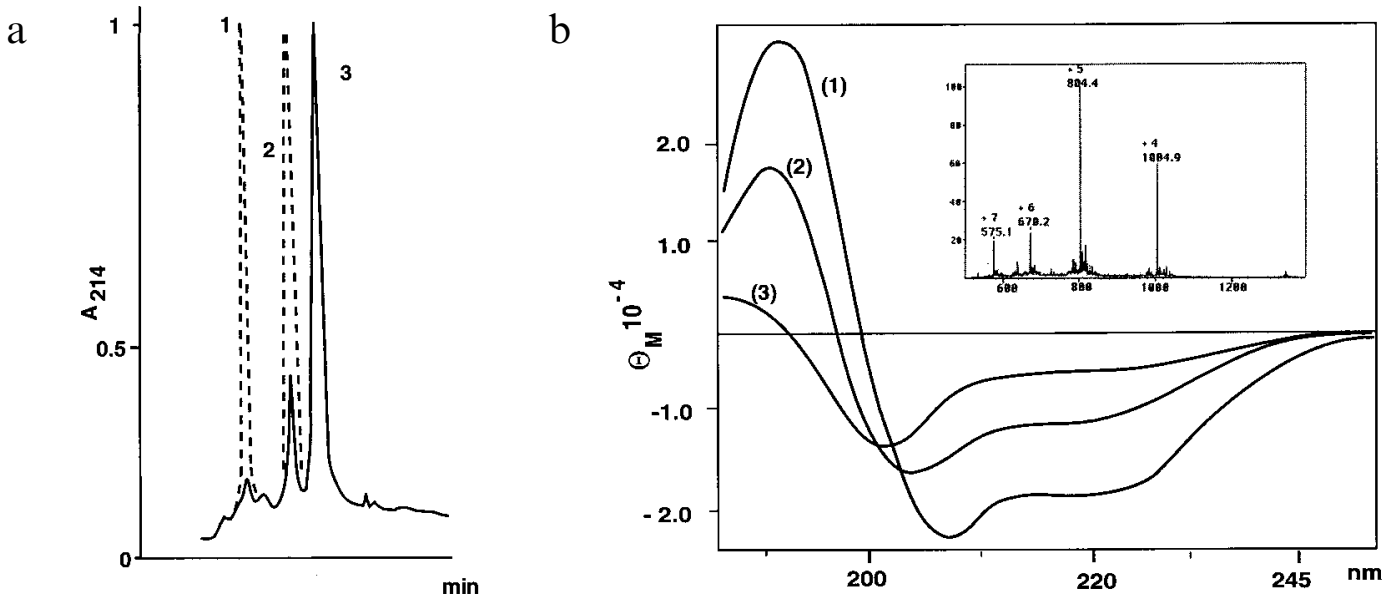

Fig. 2. (a) Reverse-phase HPLC profile of the condensation reaction of the helical block $\alpha$ to the 14-mer template (Scheme 1) after $8 \mathrm{~h}$ of reaction; 1: template; 2: helical block; 3: target product $\langle\beta \beta \alpha\rangle$ (dashed lines indicate the profile at $t=0$ ). (b) $C D$ spectra of the $\mathrm{Zn}$ (II) complexed (1) and metal free (2) $\langle\beta \beta \alpha>$. The spectrum of the single helix block is shown for comparison (3). $\mathrm{c}=6$ $\times 10^{-5} \mathrm{mM} ; 10 \mathrm{mM}$ aqueous phosphate buffer, $\mathrm{pH} 7$; inset: ESI-MS of $\langle\beta \beta \alpha\rangle$. 
Template:

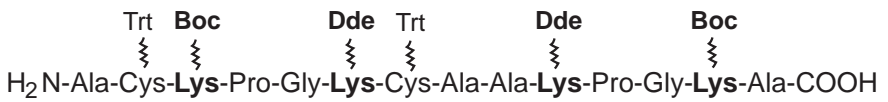

Helix: $\alpha_{1}$
1. cyclization (PyBOP, DMF)
2. - Dde $\left(10 \% \mathrm{H}_{2} \mathrm{NNH}_{2}\right.$ in DMF)
3. + Fmoc- $-\mathrm{NHOCH}_{2} \mathrm{COOH}$
4. -Boc $(95 \%$ TFA)
5. + Boc- $\mathrm{NHOCH}_{2} \mathrm{COOH}$
6. - Fmoc (20\% piperidine)

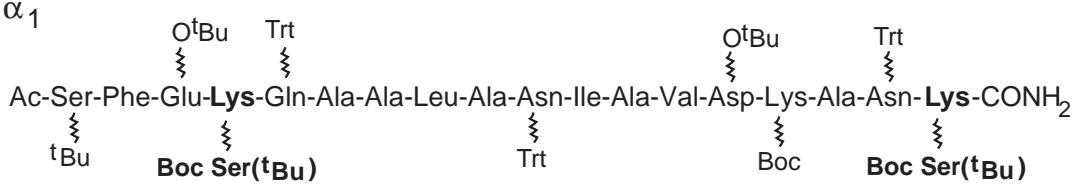

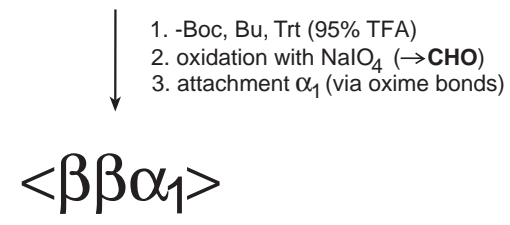

1. -Boc $(95 \%$ TFA)

Helix: $\alpha_{2}$

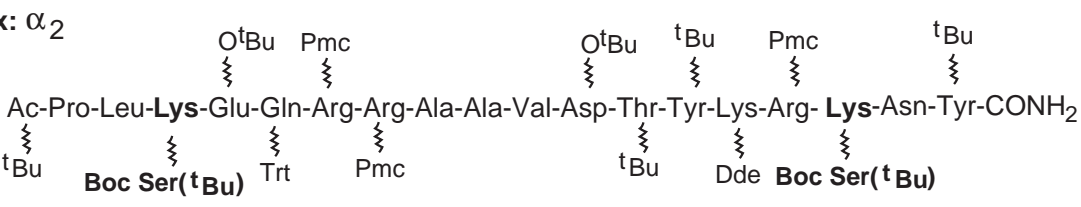

1. -Boc, Bu, Trt (95\% TFA)

2. oxidation with $\mathrm{NaIO}_{4}(\rightarrow \mathrm{CHO})$

3. attachment $\alpha_{2}$ (via oxime bonds)

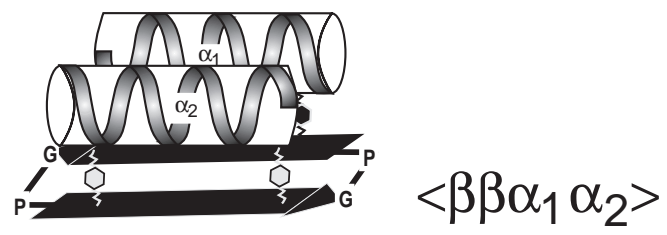

Scheme 2. Synthesis of the MHC LIF molecule $<\beta \beta \alpha_{1} \alpha_{2}>$. After cyclization and functionalization of the template molecule prepared by SPPS, sequential condensation of the helical $\alpha_{1}$ and $\alpha_{2}$ blocks via oxime bond formation in solution results in the target molecule $<\beta \beta \alpha_{1} \alpha_{2}>$. The attachment sites in the constituent blocks for the oxime bond formation are depicted in bold letters. As shown, the functional groups of the helix are obtained by $\mathrm{IO}^{-4}$ oxidation of the serine residues attached to the $\varepsilon-\mathrm{NH}_{2}$ group of the lysine residues [10]; the aminooxy functions in the template molecule were fixed to the orthogonally protected lysine side chains using aminooxy acetic acid derivatives. As potential attachment site for the antigenic peptide an orthogonal protected (Dde) lysine residue was incorporated in helix $\alpha_{2}$. 
Synthesis and conformational properties of $\langle\beta \beta \alpha\rangle$

The chemical synthesis (Scheme 1) was achieved by preparing the individual building blocks, i.e. the template molecule and the helical segment, by stepwise solid phase synthesis [16]. After cleavage from the resin and HPLC purification, the sidechain protected peptides (containing carboxylic groups at both chain ends) were reacted in aqueous solution by a one-step condensation of the helical 18-mer peptide with the cyclic template via amide bond formation. To increase the solubility of the fully protected helical block, $\mathrm{Thr}^{8}$ (Scheme 1) was protected as a dimethyl pseudo-proline (YPro) derivative [17]. Due to the pronounced structure disrupting effect of $\Psi$ Pro, the 18-mer peptide was readily soluble in a variety of organic solvents; in addition, the condensation reaction of the helix to the template proceeded to completion within a few hours (Fig. 2a, molecular weight 4015 , see inset $2 \mathrm{~b}$ ), pointing to the absence of aggregation effects of the fully protected helical block.

As suggested by molecular modeling studies [15], the zinc finger LIF preserves the essential structural and functional features of the native Zif molecule, as documented by the absorption and $\mathrm{CD}$ spectra and by the $\mathrm{Zn}$ (II) complexation properties (Fig. 2b). Contrary to the native linear polypeptide, $<\beta \beta \alpha>$ retains some of its secondary structure elements even in the absence of the zinc complex, reflecting the onset of tertiary interactions in $\langle\beta \beta \alpha>$ induced by $\mathrm{C}$ - and $\mathrm{N}$-capping of the helix block on the template.

In the search for Zif derived mimetics with novel DNA binding properties, the incorporation of non-proteinogenic building blocks offers a wide range for structural and functional modifications; moreover, the assembly to tertiary locked-in folds by a single condensation step allows for the facile access of a large number of analogues, including LIF libraries.

\section{Design and synthesis of an MHC derived locked-in fold}

In applying similar strategies as for zinc finger
LIF, the more complex MHC folding motif [18] was engineered according to our molecular kit approach in condensing two helical blocks mimicking parts of the A-chain $\left(\alpha_{1}: 53-70\right)$ and Bchain $\left(\alpha_{2}: 66-83\right)$ helix of native MHC II to a $\beta$ sheet template. By fixing both helical chain ends covalently to the template, a locked-in fold of the type $\langle\beta \beta \alpha \alpha>$ mimicking some of the structural features of the native molecule is obtained (Fig. 1b). As for the zinc finger LIF, the chemical synthesis of the MHC locked-in fold was achieved by a two-step approach (Scheme 2). First, a cyclic 14-mer peptide exhibiting two pairs of orthogonally protected aminooxy groups as attachment sites and the helical blocks (containing aldehyde groups at the $\mathrm{C}$ - and $\mathrm{N}$-terminus) were prepared by SPPS. In a second step, the sequential condensation of the two helices to the template was achieved via oxime bond formation [12,14]. The target molecule $<\beta \beta \alpha_{1} \alpha_{2}>$ was obtained in high yields and its chemical integrity was confirmed by ESI-MS (theoretical and obtained molecular weight: 6179). The elucidation of the conformational and biostructural properties of the target molecule is currently in progress.

\section{CONCLUSIONS}

The concept of locked-in folds offers an elegant way to bypass the notorious folding problem in protein de novo design. Due to the reduced conformational space, the multibranched chain architectures exhibit increased thermodynamic stability as exemplified for the zinc finger locked-in fold, thus serving as versatile scaffolds for mimicking protein function. Further elaboration of today's methodologies in chemoselective ligation and orthogonal protection techniques will further expand the scope of the present approach. Consequently, the efficient chemical synthesis of protein-like molecules may substantially contribute to our understanding of the complex interplay between protein structure and function, with interesting prospects for the design of therapeutically interesting target molecules. 


\section{ACKNOWLEDGEMENTS}

One of the authors (G.T.) is grateful for financial support granted by the Agassiz Foundation, Lausanne, Switzerland. We thank Prof. Manfred Mutter for helpful discussions.

\section{REFERENCES}

1 a. Richardson, J.S. and Richardson, D.C., Trends Biochem. Sci., 14 (1989) 304.

b. Bryson, J.W., Betz, S.F., Lu, H.S., Suich, D.J., Zhou, H.X., O’Neil, K.T. and DeGrado, W.F., Science, 270 (1995) 935.

c. Vuilleumier, S. and Mutter, M., Angew. Chem., Int. Ed. Engl., 28 (1989) 535.

d. Olofsson, S. and Baltzer, L., Folding Des., 1 (1996) 347.

e. Broo, K., Brive, L., Lundh, A.-C., Ahlberg, P. and Baltzer, L., J. Am. Chem. Soc., 118 (1996) 8172.

f. Struthers, M.D., Cheng, R.P. and Imperiali, B., Science, 271 (1996) 342.

2 a. Creighton, T.E., Proteins, Freeman, New York, NY, U.S.A., 1984.

b. Borman, S., Chem. Eng. News, 74 (1996) 29.

3 Mutter, M. and Tuchscherer, G., Makromol. Chem. Rapid Commun., 9 (1988) 437.

4 Mutter, M., Tuchscherer, G., Miller, C., Altmann, K.H., Carey, R.I., Wyss, D.F., Labhardt, A.M. and Rivier, J.E., J. Am. Chem. Soc., 114 (1992) 1463.

5 Dumy, P., Eggleston, I.M., Cervigni, S.E., Sila, U., Sun, X. and Mutter, M., Tetrahedron Lett., 36 (1995) 1255.

6 Dumy, P., Eggleston, I.M., Esposito, G., Nicula, S. and Mutter, M., Biopolymers, 39 (1996) 297.

7 Mutter, M. and Tuchscherer, G., In Symposium in Print, Highlights in Bioorganic Chemistry, Pure Appl. Chem., 68 (1996) 2153.
8 Tuchscherer, G. and Mutter, M., J. Pept. Sci., 1 (1995) 3.

9 Mutter, M., Dumy, P., Garrouste, P., Lehmann, C., Mathieu, M., Peggion, C., Peluso, S., Razaname, A. and Tuchscherer, G., Angew. Chem., Int. Ed. Engl., 35 (1996) 1482.

10 a. Choo, Y. and Klug, A., Proc. Natl. Acad. Sci. USA, 91 (1994) 11163.

b. Jamieson, A.C., Wang, H. and Kim, S.-H., Proc. Natl. Acad. Sci. USA, 93 (1996) 12834.

c. Frankel, A.D., Berg, J.M. and Pabo, C.O., Proc. Natl. Acad. Sci. USA, 84 (1987) 4841.

d. Michael, S.F., Kilfoil, V.J., Schmidt, M.H., Amann, B.T. and Berg, J.M., Proc. Natl. Acad. Sci. USA, 89 (1992) 4796.

e. Desjarlais, J.R. and Berg, J.M., Proc. Natl. Acad. Sci. USA, 90 (1993) 2256.

f. Rebar, E. and Pabo, C.O., Science, 263 (1994) 671.

11 Pavletich, N.P. and Pabo, C.O., Science, 252 (1991) 809.

12 Rose, K., J. Am. Chem. Soc., 116 (1994) 30.

13 a. Liu, C.F. and Tam, J.P., Proc. Natl. Acad. Sci. USA, 91 (1994) 6584.

b. Dawson, P.E. and Kent, S.B.H., J. Am. Chem. Soc., 115 (1993) 7263.

14 Tuchscherer, G., Tetrahedron Lett., 34 (1993) 8419.

15 Mutter, M., Lehmann, C., Mathieu, M., Rohwedder, B. and Tuchscherer, G., Proc. Natl. Acad. Sci. USA, manuscript submitted.

16 Stewart, J.M. and Young, J.D., Solid Phase Peptide Synthesis, Pierce Chemical Co., Rockford, IL, U.S.A., 1984.

17 Wöhr, T., Wahl, F., Nefzi, A., Rohwedder, B., Sato, T., Sun, X. and Mutter, M., J. Am. Chem. Soc., 118 (1996) 9218.

18 Stern, L.J., Brown, J.H., Jardetzky, T.S., Gorga, J.C., Urban, R.G., Strominger, J.L. and Wiley, D.C., Nature, 368 (1994) 215. 